\title{
Geographic and Substrate Distribution of Holocene Mollusks in Mid-Atlantic Offshore Deposits
}

Hope J. Duke ${ }^{1}$, Carmi M. Thompson², Mark H. K. Simonds ${ }^{1}$, Rowan Lockwood ${ }^{1}$, Kelvin W. Ramsey. ${ }^{3}$

(1) Dept. of Geology, The College of William and Mary, Williamsburg, VA, USA; (2) Department of Natural History,

Florida Museum of Natural History, Gainesville, FL, USA; (3) Delaware Geological Survey, University of Delaware, Newark, DE, USA

\section{INTRODUCTION}

While the paleoecology of Neogene mollusks has been studied throughout the U.S. Atlantic Coastal Plain, relatively little is known about the mollusks living on the continental shelf and how they are preserved in the Holocene record. Relationships between mollusks and the substrate in which they occur can help coastal managers target areas from which to draw sand for beach nourishment projects.

\section{RESEARCH GOALS}

1) Map offshore geographic distribution of molluscan fauna

2) Analyze relationship between abundance of mollusks and substrate

\section{STUDY LOCATION}

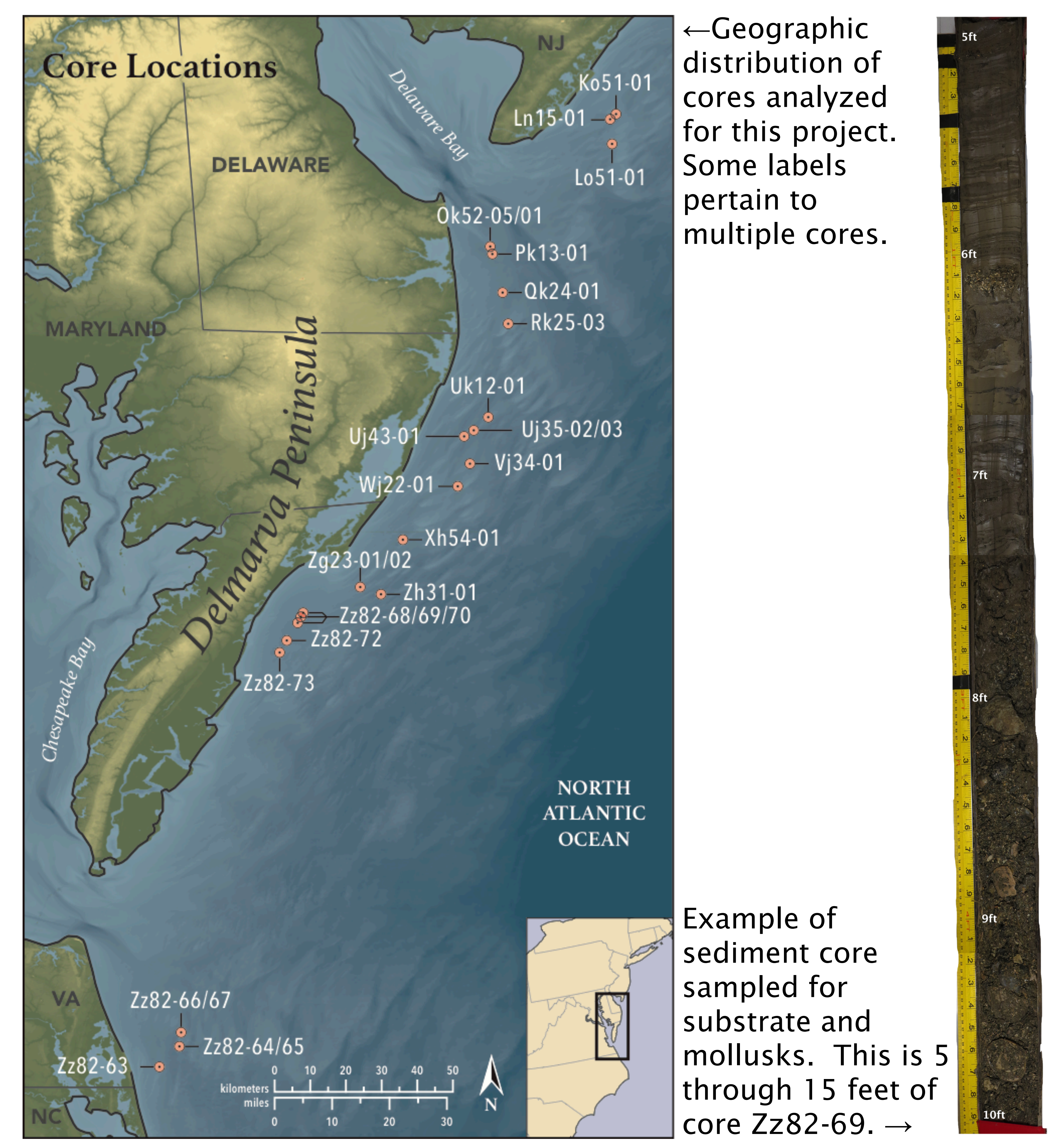

\section{METHODS}

24 cores collected in 2015 and 2016; funded by the BOEM ASAP project; described and sampled at the Delaware Geological Survey

225 samples containing shell sieved, sorted, identified, counted to $1 \mathrm{~mm}$

Spearman Rank, Chao 1 Diversity Index, and KruskalWallis used to examine relationship between substrate and molluscan abundance/diversity

- Cores: 15 - 20 feet long. Water depths: 40.2 - 60.0 feet.

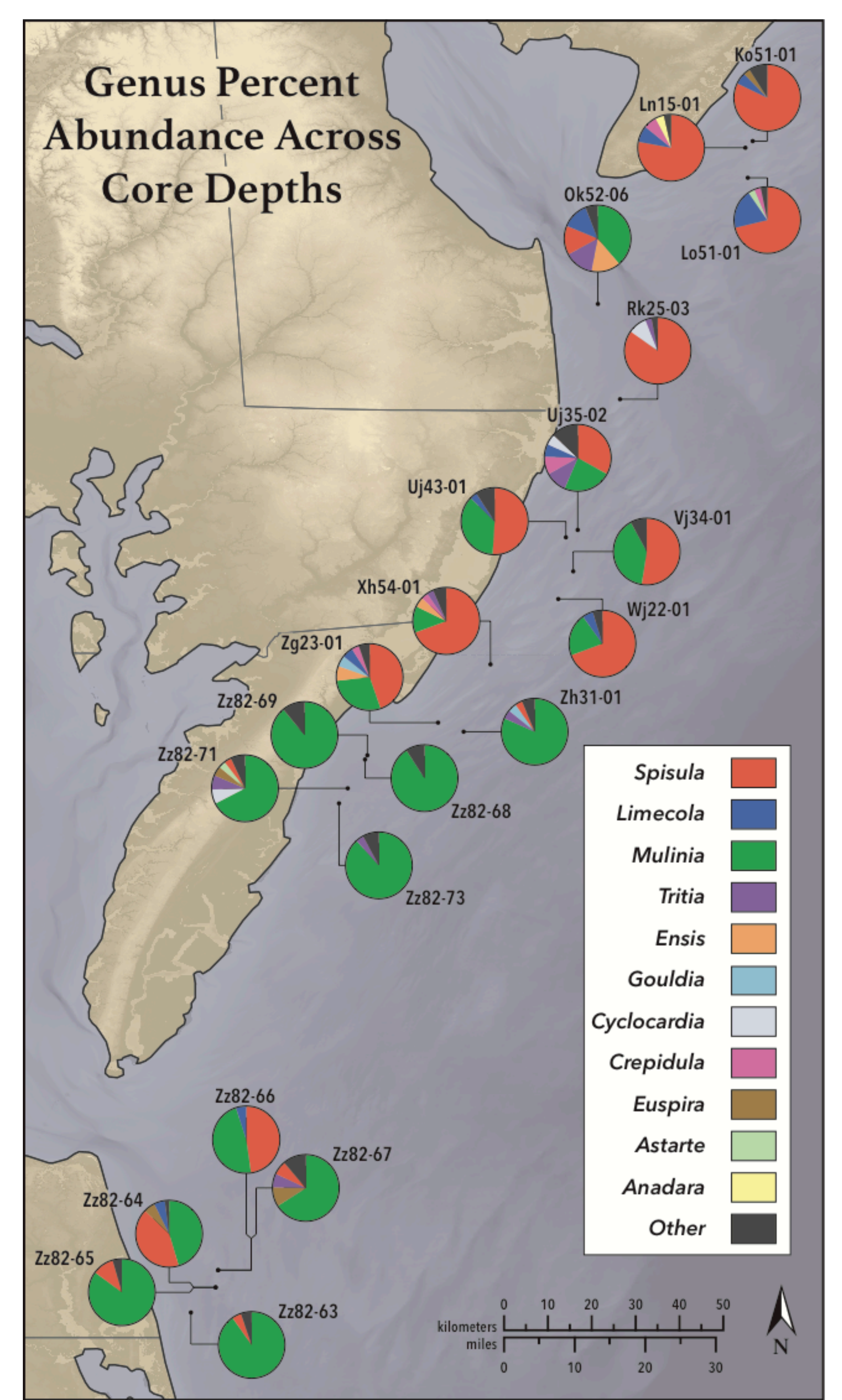

Spisula dominate in cores in the northern part of the study area, whereas Mulinia
dominate in cores towards the southern portion of the study area. Genera that comprise $3 \%$ or less of the core are categorized as other.
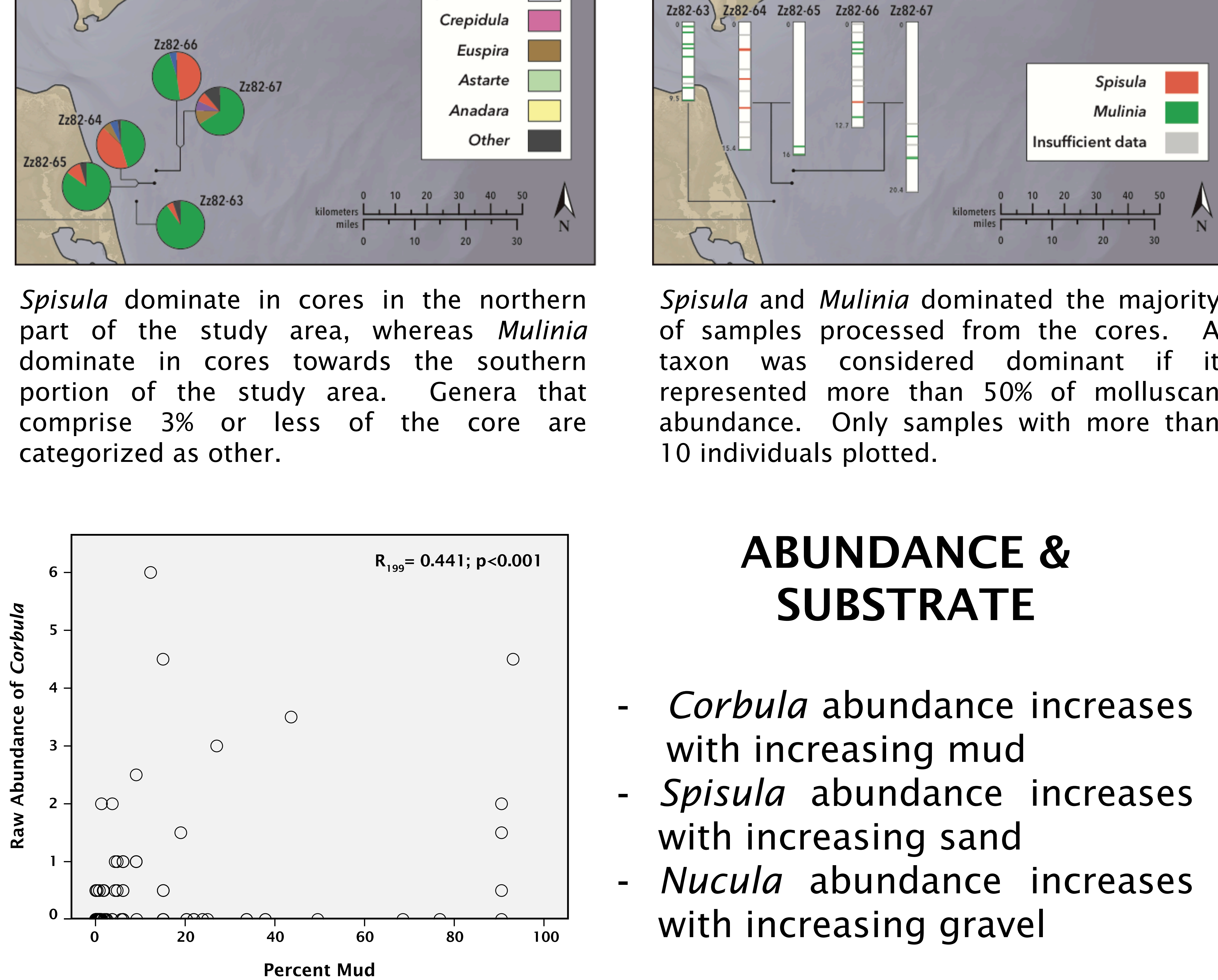

Spisula and Mulinia dominated the majority of samples processed from the cores. represented more than $50 \%$ of molluscan abundance. Only samples with more than 10 individuals plotted.

\section{ABUNDANCE \&} SUBSTRATE

Corbula abundance increases with increasing mud Spisula abundance increases with increasing sand

Nucula abundance increases with increasing gravel

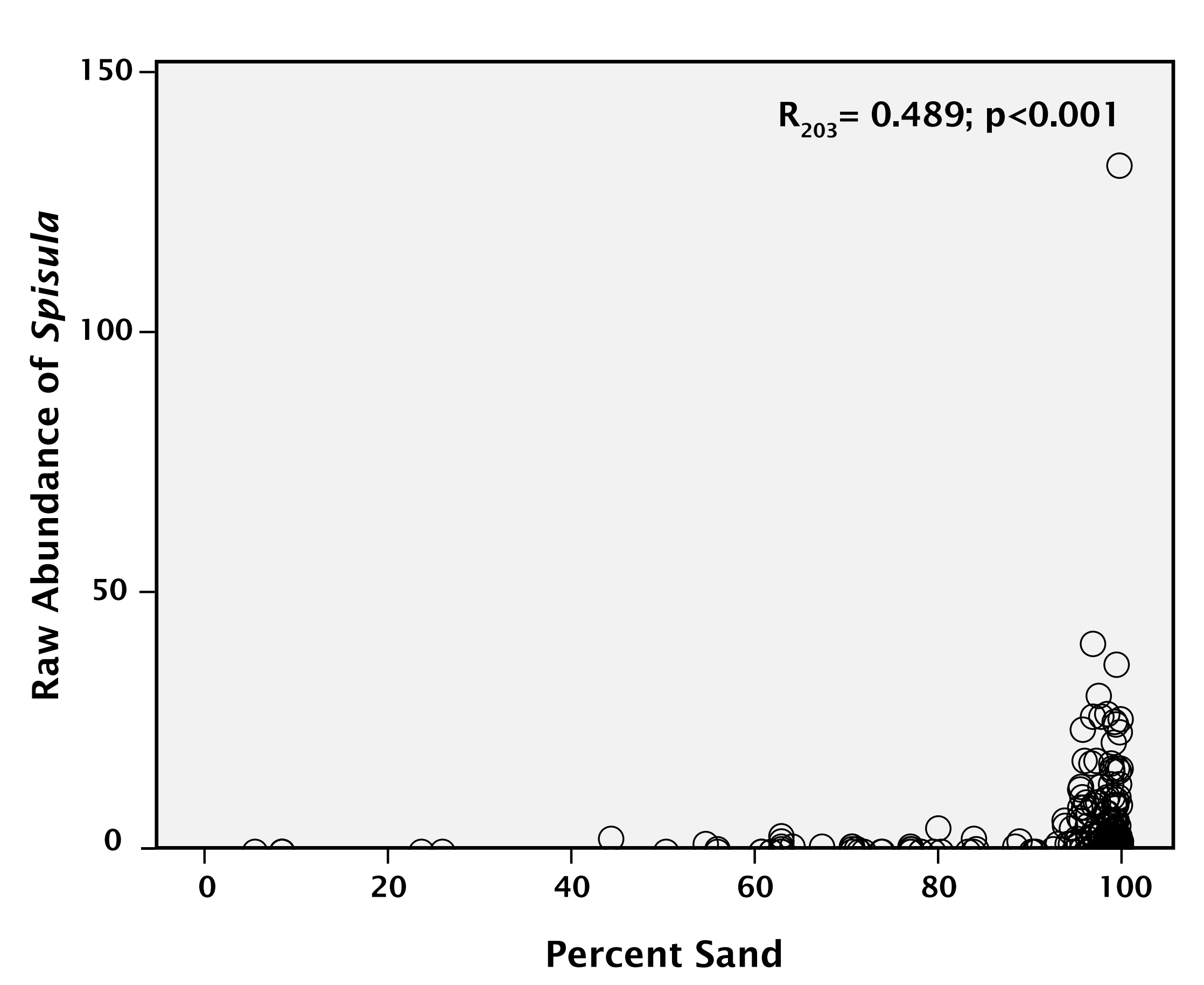

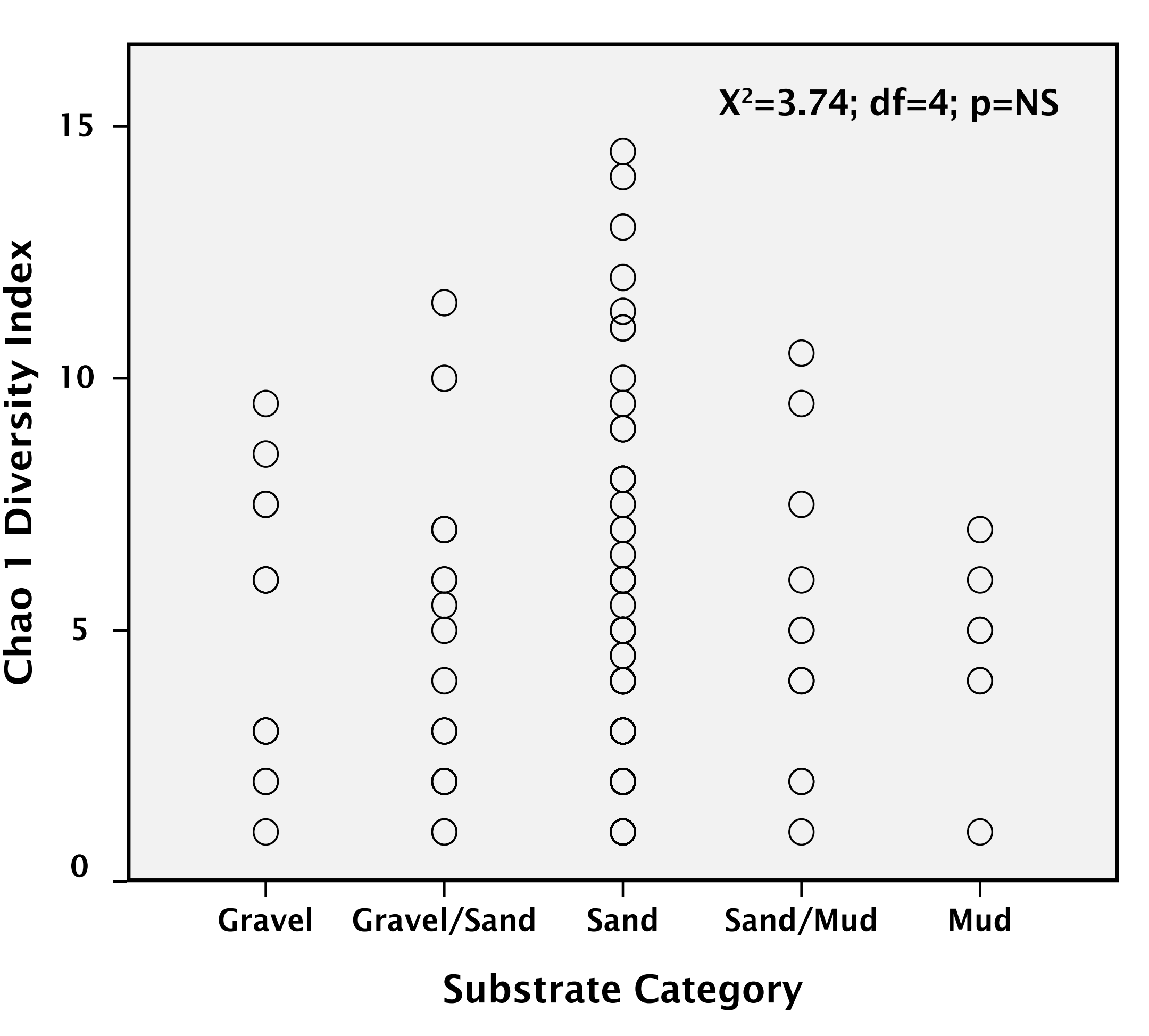

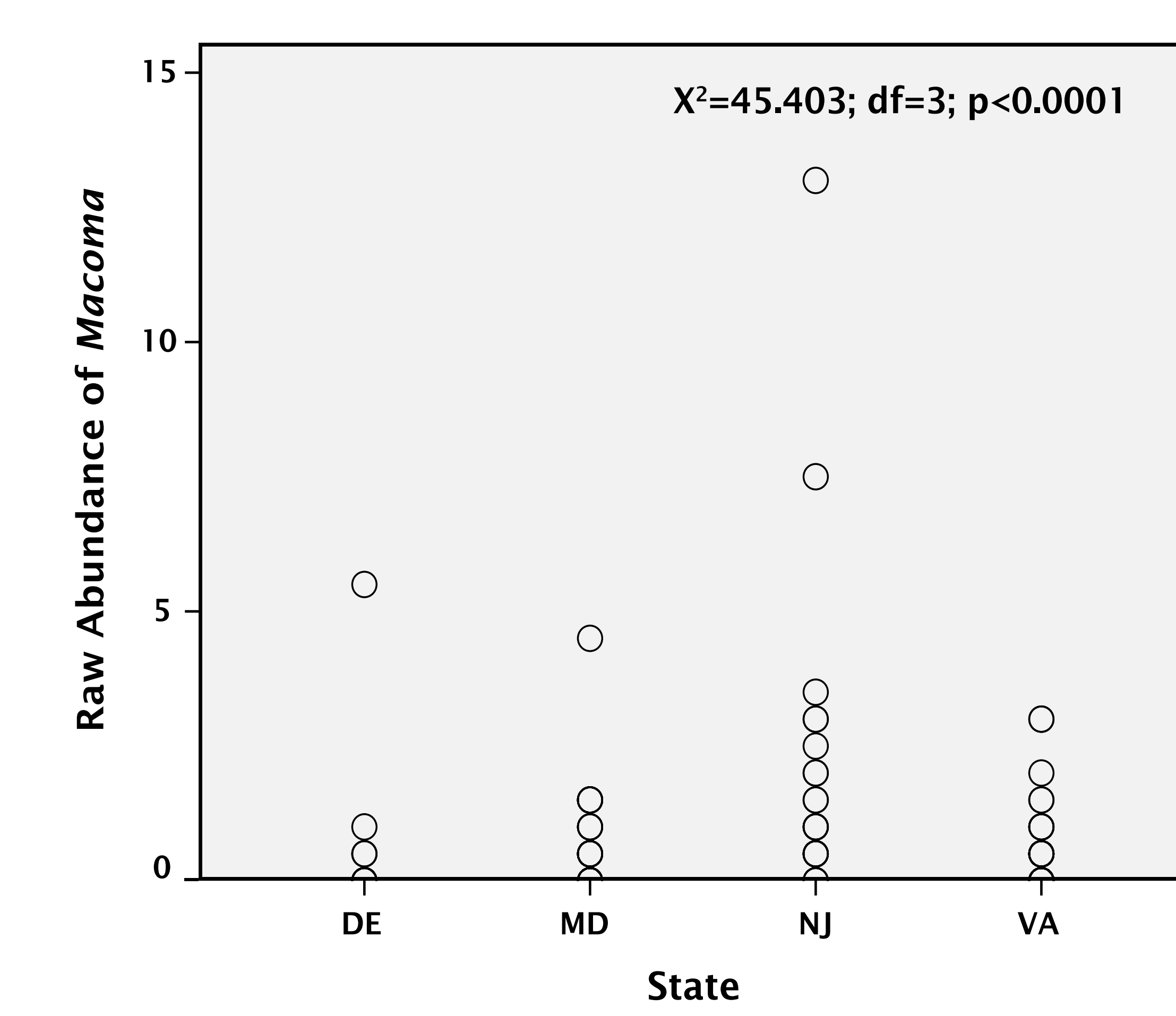

The Chao vs. Kruskal-Wallis analysis displays differences in diversity
across substrate category. Molluscan across substrate category. Molluscan
diversity is somewhat higher in diversity is somewhat higher in
sandy, versus muddy or gravelly,

The Kruskal-Wallis analysis displays states. Macoma was most prevalent in New Jersey.

\section{RESULTS}

7,030 specimens, representing 33 genera

- Specimens: 0.5 - 595.5 per sample $($ mean $=27.7)$

- Genera: 1 - 13 per sample $($ mean $=4)$

Most common taxa recorded are Mulinia, Spisula, Tritia, Limecola
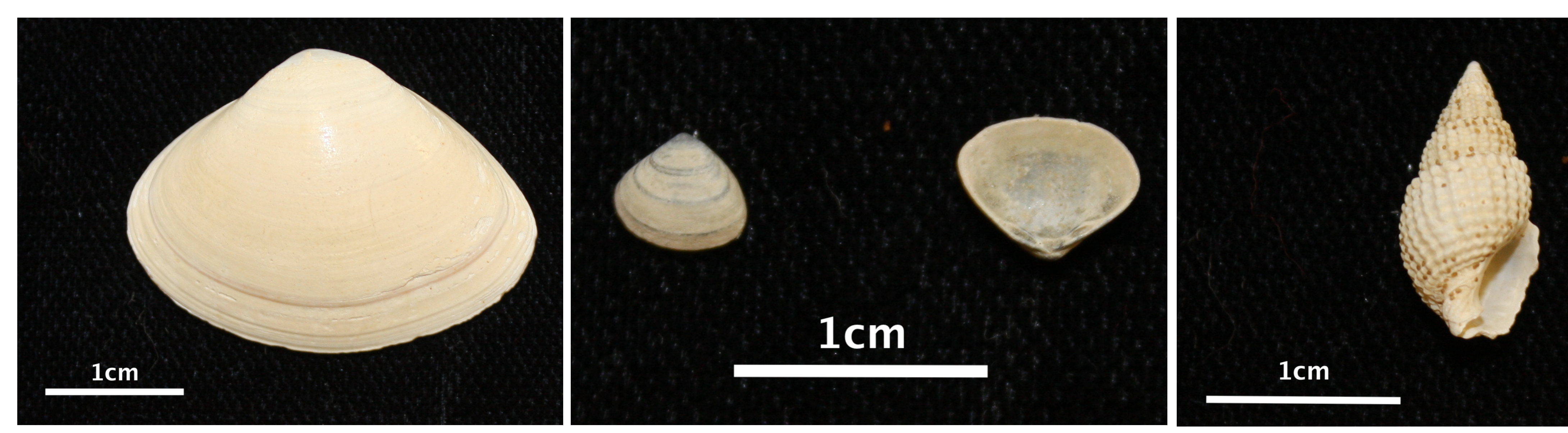

Three most abundant taxa. From left to right: Spisula, Mulinia, Tritia.

\section{CONCLUSIONS}

There is a taxonomic gradient from Spisula to Mulinia from north to south

- The strong correlation between abundance of Spisula and percent sand could be useful in determining beach nourishment sources

Samples offshore of Delaware and Maryland are more diverse than those offshore Virginia

\section{ACKNOWLEDGEMENTS}

I would like to thank the Bureau of Ocean and Energy Management for the funding that made this project possible. I am also very appreciative of the support from my advisors, co-authors, and the entire W\&M Geology department. 